\title{
FIELD EMISSION STUDIES FROM NB SURFACES RELEVANT TO SRF CAVITIES*
}

\author{
T. Wang ${ }^{\dagger}$, C. Reece, R. Sundelin, Jefferson Lab, Newport News, VA 23606, USA
}

\begin{abstract}
Enhanced field emission (EFE) presents the main impediment to higher acceleration gradients in superconducting rf (SRF) niobium $(\mathrm{Nb})$ cavities for particle accelerators. A scanning field emission microscope was built at Jefferson Lab with the main objective of systematically investigating the sources of EFE from $\mathrm{Nb}$ surfaces. Various surface preparation techniques and procedures, including chemical etching, electropolishing, ultrasonic water rinse, high pressure water rinse, air-dry after methanol rinse, air-dry after water rinse in Class 10 cleanroom, were investigated. The capability and process variables for broad-area $\mathrm{Nb}$ surfaces to consistently reach field emission free or near field emission free performance at $\sim 140 \mathrm{MV} / \mathrm{m}$ have been experimentally demonstrated using the above techniques/procedures.
\end{abstract}

\section{INTRODUCTION}

Enhanced field emission is a fundamental limitation in a wide range of high-voltage vacuum devices, for instance, $\mathrm{x}$-ray tubes, electron microscopes, power vacuum switches, klystrons, and high-field SRF Nb resonators for particle accelerators [1][2][3]. When electrons tunnel through the surface barrier of a metal into a vacuum under a high electric field, field emission of electrons occurs. This emission was explained by Fowler and Nordheim in terms of a quantum mechanical tunneling effect in 1928 [4][5]. The result is the so-called Fowler-Nordheim (F-N) law:

$$
j ? \frac{A ? E^{2}}{?} ? \exp \left(? \frac{B ? ?^{\frac{3}{2}}}{E}\right),
$$

with $A=1.54 ? 10^{-6}, B=6.83 ? 10^{7}$, current density $j$ in $\mathrm{A} / \mathrm{cm}^{2}$, electric field $E$ in $\mathrm{V} / \mathrm{cm}$, and work function ? in $\mathrm{eV}$. In practice, FE current is measured at fields much lower than that described by the F-N law, and this phenomenon is termed enhanced field emission. In order to interpret EFE, a field enhancement factor ? (> 1) is introduced and usually leads to a good approximation by the modified F-N law [6][7].

Focusing on the material used for SRF cavities, $\mathrm{Nb}$, and other relevant material, a number of institutions have conducted research in FE [8][9][10][11]. Their results show that EFE sources are localized micron or submicron sites that appear to be particles or scratches. Most emitters contain foreign elements, although the types of elements differ. The density of emission sites varies significantly on samples, possibly due to nonstandard preparation and

\footnotetext{
*Work supported by the U.S. Department of Energy, Contract No. DEAC05-84ER40150.

†tong@jlab.org
}

handling procedures. Lack of consistency in FE performance is also the dominant problem in current SRF cavities. The University of Wuppertal's findings suggest that emitter density increases with material bulk impurity content [12], however, all of their localized emitters were particles containing $\mathrm{Nb}$ and $\mathrm{Fe}$. Aimed at addressing some of the above issues, this work was undertaken with the objectives of establishing a standard preparation procedure for maximal and consistent suppression of FE, and investigating the intrinsic FE limit imposed by grain boundary and material bulk impurity in currently employed $\mathrm{Nb}$. As a result, $\mathrm{FE}$ sources from $\mathrm{Nb}$ were investigated with respect to a variety of preparation techniques, i.e., chemical etching, electropolishing, ultrasonic water rinse, high pressure water rinse, with and without methanol rinse before air-dry.

\section{EXPERIMENTAL APPARATUS AND PROCEDURES}

We designed and built an apparatus to scan and locate FE sources on material surfaces, named a scanning field emission microscope (SFEM). The detail of the apparatus was previously described by the authors [13]. The SFEM is a UHV device $\left(\sim 10^{-9}\right.$ Torr), attached to an existing Amray scanning electron microscope (SEM 1830) with a nominal resolution of several $\mathrm{nm}$. Samples are loaded via the SEM, and can be transferred under vacuum to other chambers. Within the SFEM chamber, samples slightly larger than 25-mm diameter can be moved in Cartesian $x$, $y$, and $z$ directions under an anode tip by a high-precision sample manipulator (resolution: 2.5 ?m). An anode of 150 ? m radius (cylindrical tip) and anodes of 10- and 1-? $\mathrm{m}$ tip curvature radius (paraboloid shaped) can be selected for coarse, medium, and fine scans. After emitters are accurately located by the SFEM, the sample is transferred to the SEM and emitters are then relocated with the aid of artificial markings on surface for emitter characterization. The SEM is equipped with an energy dispersive $\mathrm{x}$-ray spectrometer (EDS) capable of windowless operation for light-element sensitivity. The apparatus is located in a Class 1000 cleanroom to reduce the risk of contamination.

The electronic circuit for the experiment is illustrated in Figure 1. The high-voltage power supply is controlled by a computer to output a voltage ramp from 0 up to $40 \mathrm{kV}$ in steps of $+200 \mathrm{~V}$, until a FE current threshold, usually set at 1-2 nA, is detected by a picoammeter. Hence, detection of both strong and weak emitters is accomplished in a single scan. The gap between the anode tip and the sample is usually set at 100-200 ?m, with the accuracy maintained at ? 10 ?m. At an individual emission center, the gap and electric field can be 
calibrated, and field enhancement factor ? can be extracted [13][14].

\section{FE FROM CHEMICALLY ETCHED AND ELECTROPOLISHED NB}

In the same manner as is done with $\mathrm{Nb}$ cavities, a number of $\mathrm{Nb}$ samples made from high-purity sheets (as used in SRF cavities, RRR 300, where RRR is the ratio of resistance at room temperature to that at low temperature (normal state)), were chemically-etched by BCP (buffered chemical polish, HF (49\%): $\mathrm{HNO}_{3}(69 \%)$ $\left.: \mathrm{H}_{3} \mathrm{PO}_{4}(85 \%)=1: 1: 1\right)$ to remove the machining-damaged layer. To remove acid residue and particles on samples, ultrasonic cleaning in deionized water was performed in a Class 1000 cleanroom immediately following BCP. The samples were then methanol (electronic grade) rinsed to displace water from the surface before being placed on a filtered laminar-flow bench in the cleanroom for a few minutes to dry.

More than 20 samples were studied, and they exhibited inconsistent FE performance and often a large number of FE sites [14]. Through trial and error, the preparation and handling procedure was significantly modified. The performances from the final set of samples are illustrated in Table 1 , with a consistent 0 or near 0 emitter density achieved at $\sim 140 \mathrm{MV} / \mathrm{m}$. The emitters identified in this series of tests are all external particles. SEM picture of a selected emitter is shown in Figure 2. The established procedures, as listed below, proved critical in achieving the final results.

? Material inspection: choose $\mathrm{Nb}$ sheet free of scratches and pits using examination lens.

? Sample machining: use a designated clean area, use only plastic fixtures to minimize surface damage, change machine tools frequently to avoid embedding impurities from dull tools.

? BCP: avoid any contact with sample surfaces during BCP and sample removal from bath. Stirring of the acid is often necessary.

? Rinse and transfer: avoid any contact with the surface. Frequently replacing water during ultrasonic cleaning may be necessary. Minimize air exposure in Class 1000 cleanroom after drying.

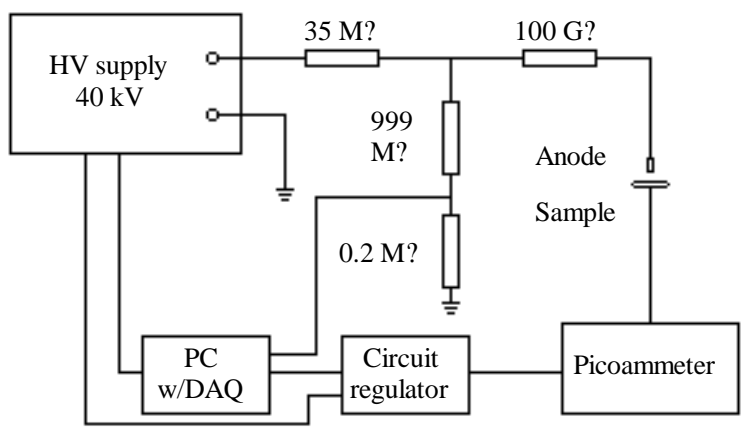

Figure 1: Experimental circuit diagram.
Table 1: FE results at $\sim 140 \mathrm{MV} / \mathrm{m}$ scanning field from the final set of BCP-etched samples. (Indicated fields are the fields that yield 2-nA FE current. The scan area for each sample is 25-mm diam. \#75-2 (300 ? m), for instance, is for sample \#75 after the 2nd surface removal, and the combined removal is $300 ? \mathrm{~m}$.)

\begin{tabular}{cc}
\hline Tests & No. of field emitters \\
\hline$\# 75-1(250$ ? $)$ & $1[35 \mathrm{MV} / \mathrm{m}(\mathrm{Nb}, \mathrm{Fe}, \mathrm{Ti}, \mathrm{Ca})]$ \\
$\# 75-2(300 ? \mathrm{~m})$ & $2[99 \mathrm{MV} / \mathrm{m}(\mathrm{Nb}), 103 \mathrm{MV} / \mathrm{m}(\mathrm{Nb})]$ \\
$\# 72-1(250$ ? $)$ & 0 \\
$\# 72-2(300 ? \mathrm{~m})$ & 0 \\
$\# 76-1(250 ? \mathrm{~m})$ & 0 \\
$\# 81-1(200 ? \mathrm{~m})$ & 0 \\
$\# 83-1(200 ? \mathrm{~m})$ & 0 \\
\hline
\end{tabular}

Another set of samples was BCP-etched, and then electropolished to remove an additional $\sim 40 ? \mathrm{~m}$ from the surface. The electropolishing (EP) method developed by Siemens, often used for $\mathrm{Nb}$ cavities [15], is used here for samples. The electrolyte formula consists of $850-\mathrm{ml}$ sulfuric acid (96\%) and 100-ml hydrofluoric acid (40\%). Rinse and drying was done in the same way as previously described. Table 2 shows the FE scan results. Compared to the surface conditions obtained by BCP, the resulting $\mathrm{Nb}$ surface is very smooth at grain boundaries [16]. The only emitter found in these tests, which caused a vacuum microdischarge, is an external particle containing $\mathrm{Nb}, \mathrm{Fe}$, and Cr. Its SEM picture is shown in Figure 2. As with

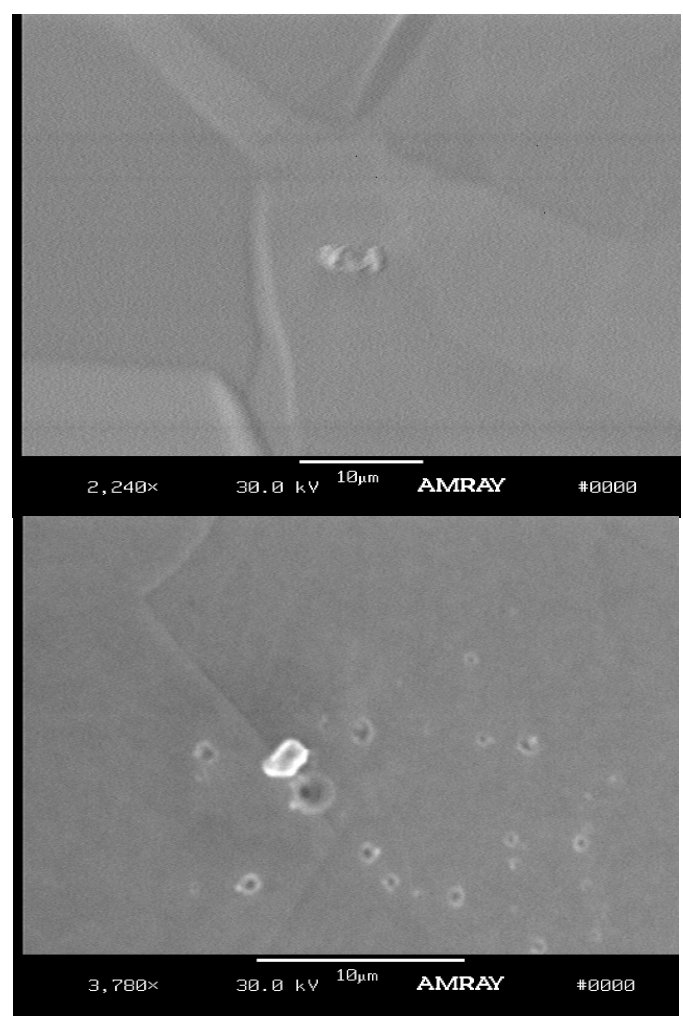

Figure 2: SEM photographs of emitters. Top: \#75-1 (site 1), BCP-etched, containing $\mathrm{Nb}, \mathrm{Fe}, \mathrm{Ti}, \mathrm{Ca}, \mathrm{E}=35 \mathrm{MV} / \mathrm{m}$. Bottom: \#65-4, electropolished, containing $\mathrm{Nb}, \mathrm{Fe}, \mathrm{Cr}$, $\mathrm{E}=105 \mathrm{MV} / \mathrm{m}$. The craters are caused by microdischarge. 
Table 2: FE results at $\sim 140 \mathrm{MV} / \mathrm{m}$ scanning field from electropolished samples.

\begin{tabular}{cc}
\hline Tests & No. of field emitters \\
\hline$\# 65-4(440$ ? $\mathrm{m}$ by & 1 \\
$\mathrm{BCP}+40 ? \mathrm{~m}$ by EP $)$ & {$[105 \mathrm{MV} / \mathrm{m}(\mathrm{Nb}, \mathrm{Fe}, \mathrm{Cr})]$} \\
$\# 61-1(330$ ? $\mathrm{m}$ by & 0 \\
$\mathrm{BCP}+40 ? \mathrm{~m}$ by EP $)$ & 0 \\
$\# 63-3(410$ ? $\mathrm{m}$ by & \\
BCP $+40 ? \mathrm{~m}$ by EP $)$ & \\
\hline
\end{tabular}

BCP-processed samples, this emitter may have been a contaminant deposited from stainless-steel machining tools based on its composition. Other possible sources for the remaining emitters are dust particles from inside the vacuum chamber and airborne dust particles in the cleanroom. The emitter density is similar for BCP and electropolished samples, and no difference caused by chemistry has been observed. An intrinsic FE limit imposed by grain boundary or native material impurity has not been observed up to $140 \mathrm{MV} / \mathrm{m}$.

\section{EFFECT OF DRYING PROCESSES}

For cavities, different labs have employed various approaches for drying after standard processing, e.g., using filtered $\mathrm{N}_{2}$ gas to blow dry, pumping out the vapor while applying heat, air-drying at Class 10 cleanroom with or without methanol/ethanol rinse. Among them, airdrying without methanol/ethanol rinse raised the concern that water may attract dust, react with residual chemicals, produce acid by dissolving carbon dioxide from air and cause corrosion, any of which could create FE sites. Therefore, a comparative study was done to investigate the effect. Three samples were BCP-etched, ultrasonically rinsed (UR), then methanol rinsed (MR) as previously described and then scanned for FE. Subsequently they were subject to high pressure water rinse (HPR)[17] before methanol rinse and a short air-drying in Class 10 cleanroom. Finally they were high pressure rinsed again and placed in Class 10 for an extended period without methanol rinse. The results, as shown in Table 3, indicated that no significant degradation in FE is observed by slow air-drying in Class 10 , provided the time duration can be controlled to be as short as possible. However, this conclusion is not expected to be applicable to a less clean environment, for instance Class 1000 or even Class 100, due to airborne dust. EDS didn't detect any foreign elements at these micron sites possibly due to its relatively large probing depth of several ?m.

Table 3: Number of $\mathrm{FE}$ and microdischarge sites identified by $140 \mathrm{MV} / \mathrm{m}$ scan for study of drying processes.

\begin{tabular}{cccc}
\hline Samples & UR+MR & HPR+MR & $\begin{array}{c}\text { HPR+n hrs. in } \\
\text { Class } 10\end{array}$ \\
\hline$\# 71$ & N/A & 0 & $1(67 \mathrm{hrs})$. \\
$\# 72$ & 1 & 0 & $1(67 \mathrm{hrs})$. \\
$\# 84$ & 1 & 2 & $4(90 \mathrm{hrs})$. \\
\hline
\end{tabular}

\section{SUMMARY}

We have observed no significant difference in FE performance from $\mathrm{BCP}$-etched and electropolished $\mathrm{Nb}$ samples, nor an intrinsic FE limit imposed by grain boundary or native material bulk impurity, up to 140 $\mathrm{MV} / \mathrm{m}$. Minimizing FE lies in minimizing contamination to $\mathrm{Nb}$ throughout the machining, chemistry and handling processes, as illustrated by this work. Extended air-drying in Class 10 cleanroom without methanol rinse didn't significantly degrade FE performance, however, this conclusion may not be applicable to a less clean environment.

\section{ACKNOWLEDGEMENT}

The authors would like to thank Larry Phillips for his help with the apparatus, and Brett Lewis and Tom Goodman with maintaining the SEM.

\section{REFERENCES}

[1] H. Padamsee, J. Knobloch, and T. Hays, $R F$ Superconductivity for Accelerators (Wiley and Sons, New York, 1998).

[2] Proc. of the 7th Workshop on RF Superconductivity, Gif sur Yvette, (1995).

[3] Proc. of the 8th Workshop on RF Superconductivity, Padova, (1997).

[4] R. H. Fowler and L. Nordheim, Proc. Roy. Soc. London A 119, 173 (1928).

[5] L. Nordheim, Proc. Roy. Soc. London A 121, 626 (1928).

[6] R. J. Noer, Appl. Phys. A 28, 1 (1982).

[7] R. V. Latham, High Voltage Vacuum Insulation (Academic Press, London, 1981).

[8] P. Niedermann, Ph. D thesis, University of Geneva, 1986.

[9] E. Mahner, G. Muller, H. Piel, and N. Pupeter, J. Vac. Sci. Technol. B 13 (2), 607 (1995).

[10] J. Tan, Proc. of the 7th Workshop on RF Superconductivity, Gif sur Yvette, p. 105 (1995).

[11] D. Moffat, et al., Proc. of the 5th Workshop on RF Superconductivity, Hamburg, p. 245 (1991).

[12] N. Pupeter, A. Göhl, T. Habermann, A. Kirschner, E. Mahner, G. Müller, and H. Piel, Proc. of the 7th Workshop on RF Superconductivity, Gif sur Yvette, p. 67 (1995).

[13] T. Wang, C. E. Reece, and R. M. Sundelin, Rev. Sci. Instru., 73 (9), 3215-3220 (2002).

[14] T. Wang, C. E. Reece, and R. M. Sundelin, J. Vac. Sci. Technol. B, (2003), to be published.

[15] H. Diepers, O. Schmidt, H. Martens, and F. S. Sun, Phys. Letter. 37A, 139 (1971).

[16] R. Sundelin, et al., IEEE Transactions on Nuclear Science 3, Vol. NS-20, 98 (1973).

[17] P. Bernard, et al., Proc. of the 1992 European Particle Accelerator Conference, p. 1269 (1992). 